Review Article

\title{
A Review of Potential Beneficial Effects of Honey on Bone Health
}

\author{
Mohd Amir Kamaruzzaman, ${ }^{1}$ Kok-Yong Chin ${ }^{1}{ }^{2}{ }^{2}$ and Elvy Suhana Mohd Ramli ${ }^{1}$ \\ ${ }^{1}$ Department of Anatomy, Faculty of Medicine, Universiti Kebangsaan Malaysia, Jalan Yaacob Latiff, Bandar Tun Razak, \\ 56000 Cheras, Kuala Lumpur, Malaysia \\ ${ }^{2}$ Department of Pharmacology, Faculty of Medicine, Universiti Kebangsaan Malaysia, Jalan Yaacob Latiff, Bandar Tun Razak, \\ 56000 Cheras, Kuala Lumpur, Malaysia \\ Correspondence should be addressed to Kok-Yong Chin; chinkokyong@ppukm.ukm.edu.my
}

Received 8 July 2019; Accepted 20 August 2019; Published 19 September 2019

Academic Editor: Min Li

Copyright (c) 2019 Mohd Amir Kamaruzzaman et al. This is an open access article distributed under the Creative Commons Attribution License, which permits unrestricted use, distribution, and reproduction in any medium, provided the original work is properly cited.

\begin{abstract}
Bone remodelling is a complex and tightly regulated process. Disruption of bone remodelling skewing towards resorption will cause osteoporosis and increase the risk of fragility fracture. Honey is a natural product containing various bioactive ingredients with health benefits, especially polyphenols. Therefore, honey may be a novel dietary supplement to prevent osteoporosis. This review aims to summarize the current evidence on the effects of honey on bone health. The evidence reported so far indicates a skeletal-beneficial effect of honey in animal models of osteoporosis. However, the number of studies on humans is limited. Honey can protect the bone via its antioxidant and anti-inflammatory properties, primarily through its polyphenol content that acts upon several signalling pathways, leading to bone anabolic and antiresorptive effects. In conclusion, honey is a potential functional food for bone health, but the dose and the bioactive contents of honey need to be verified prior to its application in humans.
\end{abstract}

\section{Introduction}

Osteoporosis is characterized by low bone mass, deterioration of bone architecture, compromised bone strength, and an eventual increase in the risk of fracture. Based on the National Health and Nutrition Examination Survey III (NHANES III), more than 9.9 million Americans were diagnosed with osteoporosis and an additional 43.1 million experience low bone density [1]. Osteoporosis is a growing problem in Asia due to the rapidly increasing elderly population [2, 3]. Approximately $13 \%$ of the Mainland Chinese adults were estimated to suffer from osteoporosis, and the disease was more prevalent in women aged $\geq 50$ years ( $40.1 \%$ versus $22.5 \%$ in men) [4]. The estimated number of osteoporosis patients in South Asian countries, like India, had increased from 26 million in 2003 to 36 million in 2013 [5]. Overall, by the year $2050,50 \%$ of the global hip fractures among population of age $\geq 50$ years will occur in Asia [5].

Oxidative stress has been hypothesized to be the contributing factors of many chronic diseases, including osteoporosis [6, 7]. Reactive oxygen species (ROS) directly promotes the formation of osteoclasts, the bone-resorbing cells, in a process mediated by receptor activation of nuclear factor-kappa-B (NF- $\kappa \mathrm{B})$ ligand (RANKL)-RANK interaction $[8,9]$. This signalling pathway involves redoxsensitive components, such as tumour necrosis factor receptor-associated factor 6 (TRAF6), Rac1 (a member of the Rho-GTPase subfamily), and nicotinamide adenine dinucleotide phosphate oxidases (NOX) [10]. Oxidative stress also mediates the induction of mitochondrial dysfunction apoptosis [11, 12] and decreases the differentiation and activities of osteoblasts, the bone-forming cells [13].

Age-related chronic inflammation also plays an essential role in the pathogenesis of osteoporosis by influencing bone remodelling [14]. In the presence of RANKL, the cytokines TNF- $\alpha$, interleukins (IL)-6, and IL- 1 will cause an excessive formation of osteoclasts while inhibiting osteoblast activities [15]. Proinflammatory cytokines like TNF- $\alpha$ also stimulates osteoclast development and increases the production of macrophage colony-stimulating factors (M-CSF) by bone 
marrow stromal cells (BMSCs) [16, 17]. They also suppress osteoblasts from releasing the RANKL decoy receptor, osteoprotegerin (OPG). This decoy primarily prevents the binding of RANKL with its corresponding receptor to stimulate osteoclastogenesis [15].

Calcium with or without vitamin $\mathrm{D}$ is the currently recommended prophylaxis for osteoporosis. For women of age $\geq 50$ years, the recommended daily calcium intake is $1000 \mathrm{mg}$ (dietary or supplementary) [18]. However, some studies suggested that excessive calcium supplementation is associated with cardiovascular events [19]. A meta-analysis revealed that calcium supplements without vitamin D significantly increases the risk of myocardial infarction (relative risk: $1.27,95 \%$ confidence interval (CI): 1.01-1.59) [19]. The risk of cardiovascular events is predominantly observed in studies with the intakes of higher doses of calcium supplements (1000-2000 mg), whereas anything lower is deemed safe [21]. The Women's Health Initiative study showed that the relative risk for myocardial infarction in women taking calcium with or without vitamin D was 1.24 (95\% CI: $1.07-1.45, p=0.004)$ and 1.15 (95\% CI: 1.03-1.27, $p=0.009)$, respectively, for the composite of myocardial infarction or stroke [19]. Barring the safety concerns of calcium supplementation, ensuring adequate dietary calcium intake is undoubtedly the first and the foremost step in osteoporosis prevention. However, there is a need to look for an alternative agent in preventing osteoporosis for those who are contraindicated to take calcium supplements.

Considering the involvement of oxidative stress and inflammation in the pathogenesis of osteoporosis, a functional food with properties that can counteract these processes may be a suitable prophylactic agent to prevent bone loss. Honey is one of the natural products with such properties. It is a sweet, viscous liquid substance produced mainly by a group of honeybees (from the genus Apis), which is best known worldwide due to the commercial production and human consumption for health maintenance [7]. It is stored in wax-form structures called honeycombs after being produced by honeybees from plants (floral nectar) through regurgitation, enzymatic activity, and water evaporation in the beehives. Apart from the nectar source, honeybees also collect secretions from insects (belonging to the genus Rhynchota) to produce honey called honeydew honey [22]. From nutritional view, it represents a unique source of natural macro- and micronutrients, including fructose and glucose, which make up the majority of the honey constituents. In addition to these, there is a wide range of beneficial minor constituents, especially phenolic compounds [23].

Honey also contains enzymes, amino acids, proteins, flavonoids, phenolic acids, organic acids, vitamins, and minerals in lower quantities [23]. Polyphenols, which covers a wide range of phytochemicals that are extensively studied by scientists for their health-promoting potential, can be found in almost all types of natural honey. Some of the polyphenols found in honey include flavonoids (such as apigenin, pinocembrin, kaempferol, quercetin, galangin, chrysin, and hesperetin) and phenolic acids (such as ellagic, caffeic, p-coumaric, ferulic, 3-hydroxybenzoic, chlorogenic, rosmarinic, vanillic, gallic, benzoic, and ascorbic acids) [24]. Most of these compounds work by interacting with each other to produce a range of synergistic antioxidant properties. Many published studies denote that honey possesses antioxidant, antibacterial, antiviral, anti-inflammatory, antiulcerous, immune-modulating, vasodilative, hypotensive, hypocholesterolemic, and antitumour activities [25].

In this review, evidence regarding the effects of honey on bone health derived from cellular, animal, and human studies was included. The information presented in this review will help to decide on the efficacy of honey as a functional food component in osteoporosis prevention. We will first summarize the evidence on the antioxidant and anti-inflammation properties of honey, before discussing its skeletal benefits.

\section{Antioxidant Properties of Honey}

The antioxidant activity in honey is primarily attributed to the presence of phenolic compounds and flavonoids [26]. Phenolic compounds exert antioxidant activities via several different mechanisms, such as free radical scavenging, hydrogen donation, singlet oxygen quenching, and metal ion chelation [27]. The total phenolic content (TPC) of honey can be determined through the Folin-Ciocalteu method. Physically, a higher TPC is indicated by the colour of the honey, whereby honey with a darker appearance tends to have a higher TPC as compared to the lighter one [28, 29]. Other measures to determine the antioxidant potential of honey include 1,1-diphenyl-2-picrylhydrazyl scavenging assay, 2,2' -azino-bis(3-ethylbenzothiazoline-6-sulphonic acid) assay, oxygen radical absorbance capacity assay, and ferric reducing antioxidant power assay [30].

The phenolic and flavonoid contents of honey can correct the redox imbalance in the body by counteracting the deterioration caused by oxidants such as oxygen, hydroxide, superoxide, and/or lipid peroxyl radicals [31]. The synergistic effect of exogenous nonenzymatic antioxidants in honey can be observed when they provide support for endogenous antioxidant enzymes, such as superoxide dismutase (SOD), catalase (CAT), and glutathione peroxidase (GPX), to eradicate ROS. One type of antioxidant may not be sufficient to ameliorate the damaging effect of oxidants. In contrast, it may be transformed into a pro-oxidant. In this regard, honey is advantageous by having several antioxidant constituents, which can assist each other to regenerate and prevent the formation of pro-oxidants $[32,33]$. Additionally, both enzymatic and nonenzymatic antioxidant contents in honey may act at different cellular levels, by preventing oxidation of the macromolecules or stimulating gene expressions, which ultimately provoke an antioxidant response $[31,34]$. Offsprings of rats fed with Tualang honey also had a higher GSH level and a lower lipid peroxidation level in their spinal cord tissue after being challenged with formalin-induced stress [35]. Apart from interacting with oxidants physically, polyphenols in honey can activate intracellular signalling cascades, such as phosphatidylinositol-4,5bisphosphate 3-kinase (PI3K), protein kinase B (PKB)/Akt, tyrosine kinases, protein kinase $\mathrm{C}(\mathrm{PKC})$, and mitogenactivated protein kinases (MAPKs) [36]. 


\section{Anti-Inflammatory Effects of Honey}

Oxidative stress plays a pathogenic role in chronic inflammatory diseases [37]. The production of free radicals like hydrogen peroxide $\left(\mathrm{H}_{2} \mathrm{O}_{2}\right)$ by leukocytes plays a role in inflammation, whereby it is responsible for the oxidative activation of NF- $\kappa \mathrm{B}$. The NF- $\kappa \mathrm{B}$ then regulates the expression of various genes encoding proinflammatory mediators such as cytokines, chemokines, growth factors, and inducible enzymes [38]. Several proinflammatory mediators are released during an inflammatory response, including cyclooxygenase2 (COX-2), IL-6, IL-12, interferon (INF-c), TNF- $\alpha$, and inducible nitric oxide synthase (iNOS) [39]. The activity of iNOS is stimulated during inflammation by bacterial endotoxins such as lipopolysaccharide (LPS) and cytokines, including TNF- $\alpha$ and ILs, to enhance the production of gaseous free radical, nitric oxide (NO) [40]. Together, both $\mathrm{H}_{2} \mathrm{O}_{2}$ and NO may promote self-amplification of the inflammatory response, causing cellular damaging effects.

Evidence suggested that there are several possible antiinflammatory mechanisms of honey. It inhibits the production of proinflammatory mediators, such as $\mathrm{NO}$, prostaglandin $\mathrm{E}_{2}$ $\left(\mathrm{PGE}_{2}\right), \mathrm{TNF}-\alpha$, and IL-6 in studies of carrageenan-induced inflammation model in rats [40-42]. The inhibition of TNF- $\alpha$ and $\mathrm{NO}$ expression by honey in vitro was also observed [43]. In a dextran sodium sulfate-induced ulcerative colitis rat model, the honey-treated group had significantly improved macroscopic (stool) and microscopic scores (regular folding of colonic mucosa with epithelia, crypts, submucosa, musculosa, and serosa) as well as down-regulation of oxidative (SOD and GSH), inflammatory (TNF- $\alpha$ and iNOS), and apoptotic (caspase-3) markers [44]. Albumin denaturation inhibition, membrane stabilization, and proteinase inhibition assays indicated that flavonoid extracts from $M$. beecheii honey showed anti-inflammatory activity [45]. Honey also attenuated NF- $\kappa$ B translocation to the nucleus, thus inhibiting $\mathrm{I} \kappa \mathrm{B} \alpha$ degradation with a subsequent decrease of inflammatory mediators COX-2 and TNF- $\alpha$ [46]. Each of the phenolic compounds in honey also possesses anti-inflammatory activity as shown in Table 1 . For instance, garlic acid, a type of phenolic acids found in honey, exerts an anti-inflammatory action by suppressing COX-2, thereby inhibiting the production of proinflammatory cytokines and chemokines. The biological actions of NF- $\kappa \mathrm{B}$, including the activation of transcription and DNA binding activity, are regulated by the acetylation of p65 [69]. Garlic acid inhibited p65 acetylation-dependent activation of NF- $\kappa$ B and production of inflammatory markers. The low acetylation rate of p65 resulted in a complete loss of function of NF- $\kappa \mathrm{B}$ [70]. All of these bioactive compounds may act synergistically to contribute to the overall anti-inflammatory properties of honey.

\section{Effects of Honey on Animal Models of Osteoporosis}

4.1. Normal Animals. Honey is a commonly used sweetener consisting of carbohydrates, such as fructose, glucose, and raffinose. Despite not being as prominent as fructose and glucose in honey, various animal model studies have observed the calcium uptake-enhancing effects of raffinose [71, 72].
Calcium absorption in the rats following acute (2 days) and chronic feeding (8 weeks) of Pure U.S. Fancy White Honey had been studied. Ariefdjohan et al. found an increase in calcium absorption with an acute feeding of $500 \mathrm{mg}(25.5 \%)$ or $800 \mathrm{mg}$ (33.6\%) of a honey, glucose-fructose mixture (17.1\%) or high raffinose content (25.6\%) as shown in calcium analysis from the right femur of the rats [73]. However, this calcium absorptionenhancing effect did not persist with a chronic feeding of 5\% nor $10 \%$ honey in six-week-old growing rats [73].

Another study showed that the tibial calcium content was improved by the addition of honey at $20 \mathrm{ml} / \mathrm{L}$ to drinking water starting from day 28 until day 56 in heatstressed broiler chickens [74]. This observation indicates that honey improves the calcium metabolism of the broilers [72]. There was also an improvement in the bone density of the broilers receiving honey supplementation, but the volume of their tibial bones was not affected by honey [74].

The long-term effects of feeding honeydew honey at the dose of $10 \% \mathrm{w} / \mathrm{w}$ diet for one year in comparison with sucrose and a sugar-free diet on weight gain, lipid profiles, and body composition (using dual-energy X-ray absorptiometry) in rats were examined [75]. The results showed that bone mineral density was significantly increased in the honey-fed rat group compared with the sugar-free diet group, but no differences in lipid profiles were found [75]. No differences in bone mineral density were observed between the honey- and sucrose-fed rats, although it was significantly higher in the honey-fed rats compared with the rats fed with a sugar-free diet. Honey also altered other metabolic parameters. The HbAlc levels were significantly reduced, and the HDL-cholesterol levels were significantly increased in the honey-fed group as compared with rats fed with sucrose or a sugar-free diet. Other indices in lipid profile among these three groups were similar. The favourable metabolic effects of honey may be due to the differences in the glycaemic index between honey and sucrose, as well as its antioxidant content. Thus, honey may be an osteoporosis-preventing agent for individuals who also suffer from poor glycaemic control or at risk for coronary heart disease.

4.2. Ovariectomized Rats. Postmenopausal osteoporosis occurs after the cessation of oestrogen production by the ovaries. The loss of the protective effects of oestrogen has a direct impact on the maintenance of bone health. It also gives rise to oxidative stress and inflammatory-mediated bone loss [76]. Ovariectomy is commonly used as a model of oestrogen deficiency due to the ability to mimic menopause in women [77]. Ovariectomized rats suffer from progressive bone loss similar to postmenopausal women [78]. Ovariectomized rats were used by Zaid et al. to determine the effects of Tualang honey on the female reproductive organs, tibial bone, and hormonal profile. Tualang honey is produced by Apis dorsett bees as they build beehives on the Tualang tree found in tropical rainforests. It was revealed that administration of Tualang honey at doses $0.2 \mathrm{~g} / \mathrm{kg}$ and $1.0 \mathrm{~g} / \mathrm{kg}$ for 2 weeks to ovariectomized rats significantly preserved the weight of the uterus and thickness of the vaginal epithelium, restored the morphology (trabecular thickness) of the tibial bones, and reduced the body weight compared to the untreated rats. The circulating levels of oestradiol and progesterone in the 
TABle 1: Anti-inflammatory properties of common phenolic compounds found in honey.

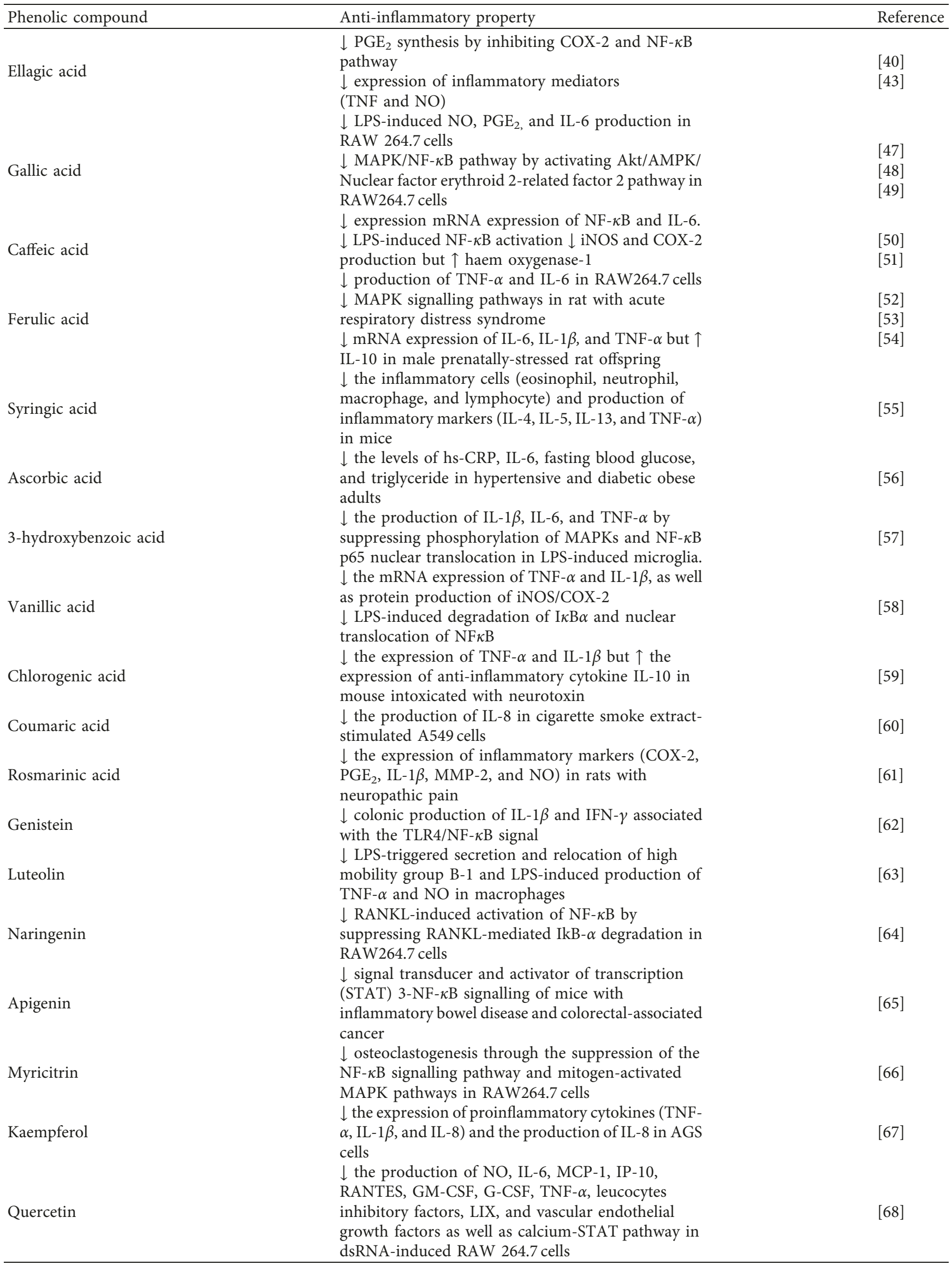


Tualang honey-treated groups were markedly lower than the untreated group. However, at the low dose $(0.2 \mathrm{~g} / \mathrm{kg})$, Tualang honey increased serum-free testosterone levels in the ovariectomized rats, which might be protective against bone loss. It remained uncertain if Tualang honey promoted the conversion of oestrogen to androgen. The phenotypic changes induced by Tualang honey could be mediated by changes in hormone levels, especially androgens [79].

Another study by Zaid et al. compared the protective effects of Tualang honey and calcium supplementation on the trabecular bone structure in ovariectomized rats [80]. Rats receiving Tualang honey at $0.2 \mathrm{~g} / \mathrm{kg}$ body weight for six weeks showed better bone structural parameters which was marked by an increase in bone volume (BV/TV), trabecular thickness (Tb.Th), and trabecular number (Tb.N) while decreasing intertrabecular space. The improvements caused by Tualang honey were superior to the $1 \%$ calcium supplementation in drinking water. It should be noted that these rats were not fed with calcium-deficient diet, so additional calcium supplementation did not seem to confer additional skeletal effects as compared to honey. Therefore, Tualang honey may be a viable prophylactic agent to prevent bone loss in postmenopausal women [80].

Manuka honey combined with $\alpha$-cyclodextrin (Manuka Honey with Cyclopower ${ }^{\mathrm{TM}}$ (MHCP)) was developed to enhance the delivery of honey and improving its water solubility and stability [81, 82]. Katsumata et al. demonstrated that MHCP decreased the serum C-terminal telopeptide of type I collagen (a marker for bone resorption), femoral RANKL (stimulator of osteoclast formation), and nuclear factor of activated T-cells, cytoplasmic 1 mRNA expression (regulators of osteoclast formation) without any effect on uterine weight in ovariectomized mice. In addition, MHCP increased caecal bifidobacteria and bacteroid contents. These results suggested that the MHCP possesses prebiotic effects which potentiate the effects of honey by decreasing bone resorption in ovariectomized mice through suppressing inflammation [83].

Supplementation of Tualang honey at the dosage of $2 \mathrm{~g} / \mathrm{kg}$ and $4 \mathrm{~g} / \mathrm{kg}$ for 12 weeks in the study by Yudaniayanti et al. was found to increase biomechanical strength of the right femoral bone in ovariectomized rats [84]. This observation showed that honey could prevent bone fragility induced by oestrogen deficiency [84]. However, Tualang honey did not preserve lumbar calcium ash density in the study by Ibrahim et al. [85]. In fact, rats receiving $3 \mathrm{~g} / \mathrm{kg}$ of honey possessed the lowest lumbar calcium ash density compared to the sham group [85]. This could have happened due to the dosage of honey that was rather high, leading to an induction of diabetes in the rats, which, in turn, promoted bone loss. However, this remained as a speculation as glucose homeostasis was not determined in their study.

4.3. Fracture Bone Healing. In a study investigating the fracture healing properties of honey and hydroxyapatite in rats, a significantly better fracture healing was seen through better bone formation, union, and remodelling on the radiograph score in the rats with honey autograft as compared to the other treatment groups at the second week. The rats treated with honey alone showed the poorest healing based on the radiograph score throughout the treatment period. Histopathological investigations revealed that the group treated with hydroxyapatite alone showed the poorest results in bone marrow formation compared to all other treatment groups. Therefore, honey and hydroxyapatite together appeared to exert better healing effects on bone defects as compared to using them separately [86].

Bone healing effects of honey was examined by Hajizadeh et al. using a mandibular bone defect healing model in rats [87]. A $2 \times 2 \mathrm{~mm}$ defect was created with an extraoral incision at the mandibular angle. In the experimental group, the defect was filled with sterile honey, under the brand of Medihoney (Derma Sciences Inc., Princeton, USA). The defect was left unfilled in the control group. After two weeks, five samples of the experimental group were in the mineralization phase, while all samples of the control group were in the vascularization phase. After four weeks, the defects were filled in four samples of the experimental group, while all samples of the control group were in the mineralization stage. The histomorphometric assessment revealed that new bone formation in the experimental group was significantly better than the control group after two and four weeks. This study demonstrated that honey could increase and accelerate bone repair of small mandibular defects in rats [87].

Grayanotoxin (GTX) is a toxin found in the flower parts of plant species such as Rhododendron and Kalmia. It is present in rhododendron pollens and can also be found in honey produced from this regional plant. This toxin-containing honey is locally known as "mad honey", and it is used for alternative therapies [88]. In a study comparing the effects of GTX-containing honey (mad honey) at $80 \mathrm{mg} / \mathrm{kg} /$ day, normal honey at $80 \mathrm{mg} / \mathrm{kg} /$ day, and propolis at $200 \mathrm{mg} / \mathrm{kg} /$ day on fracture healing, Sahin et al. showed that GTX-containing honey and propolis accelerated healing of artificial transverse fracture over the course of 30 days [89]. GTX and propolis may share similar therapeutic effects in healing bone fracture [89].

4.4. Combined Effects of Honey Supplementation and Exercise on Bone Health. Ooi et al. investigated the combined effects of eight-week jumping exercise and honey supplementation on bone health in rats [90]. The honey (type and composition not indicated) was orally supplemented to the rats at the dosage of $1 \mathrm{~g} / \mathrm{kg}$ body weight/day via oral gavage, $30 \mathrm{~min}$ before the jumping exercise. Each rat was subjected to the exercise for a five-minute duration per day for five days per week. The combination regime elicited superior effects on the tibial bone geometry and mechanical properties as compared to the jumping exercise or honey supplementation alone in rats. However, there were no statistically significant differences in bone mineral density among the experimental groups [90], which might require more time to observe an effect.

Tavafzadeh et al., through three separate studies, investigated the effects of jumping exercises in combination with honey supplementation on bone properties in young female rats [91-93]. Each rat was subjected to the exercise for five minutes per day for five days per week. Tualang honey was orally supplemented to the rats at the dosage of $1 \mathrm{~g} / \mathrm{kg}$ body mass/rat/ 
day via force-feeding, 30 min prior to the jumping exercise for a duration of eight weeks [91,92], while another study by the Tavafzadeh et al. [93] lasted for 8 and 16 weeks. From the first study, they found that the combination of honey and jumping exercise elicited more prominent beneficial effects on the tibial and femoral bone. This was shown by the increase in tibial wet and fat-free dry weights, tibial and femoral maximal load, tibial midshaft minimum diameter, and femoral midshaft maximum diameter compared to either jumping exercise or honey supplementation alone in young female rats [91]. In the second study with the same method, the combined regime significantly reduced bone resorption and enhanced antioxidant status indicated by lower serum C-terminal telopeptide of type 1 procollagen and higher serum total antioxidant status, respectively, but did not alter oxidative stress marker [92]. In the third experiment, Tavafzadeh et al. showed that continuous 16 weeks of combined jumping exercise and honey supplementation caused more beneficial effects on the tibial bone. This was evidenced by greater tibial maximum force, energy, proximal total bone density, proximal trabecular bone density, midshaft cortical bone density, cortical area, and midshaft cortical moment of inertia in the rats receiving combinational therapy as compared with individual therapy [93]. Moreover, the beneficial effects of the combinational therapy on the tibial bone properties could still be maintained even after eight weeks of cessation of exercise and supplementation [93].

Mosavat et al. investigated the effects of high and lowintensity jumping exercise combined with honey on bone and gonadotrophins [94]. The low-intensity jumping exercise was defined as 20 jumps per day for five days/week for eight weeks, while the high-intensity jumping exercise was defined as 80 jumps per day for five days/week for eight weeks. The results showed that honey supplementation combined with high-intensity exercise invokes a greater increase in the tibial and femoral mass, serum total calcium, and alkaline phosphatase (ALP) levels. The hormonal changes were not observed in the combined honey and exercise groups. Serum luteinizing hormone concentrations were significantly greater in honey combined with the low- and high-intensity exercise group compared with the high-intensity exercise-alone group [94]. Mosavat et al. further evaluated the stress hormones and showed that the serum cortisol level was higher, while the serum progesterone level was lower in the group undergoing low- and high-intensity exercise alone compared with the control group [94]. In contrast, the combined honey plus exercise group had significantly lower serum cortisol and higher serum progesterone levels compared with the exercise alone group, which signifies the role of honey in regulating hormonal balance required for normal bone remodelling. For the reproductive system in these rats, the relative weight of the excised uterus was significantly greater in the honey plus lowintensity exercise group compared to the control group, indicating that it may have oestrogenic properties [95].

\section{Human Study}

5.1. Effects of Honey versus Hormonal Replacement Therapy. In a randomized controlled trial, 79 healthy postmenopausal women aged 45-60 years who were naturally menopausal for more than one year, not on hormonal replacement therapy (HRT) for more than three months and with a body mass index $18-35 \mathrm{~kg} / \mathrm{m}^{2}$, were selected to test the effects of Tualang honey (dose of $20 \mathrm{~g} /$ day) and HRT (contain $1 \mathrm{mg}$ oestradiol valerate and $5 \mathrm{mg}$ dydrogesterone) on cardiovascular risk factors, hormonal profiles, and bone mineral density. It was found that there were no significant differences in the bone density, blood sugar level, and lipid profile between the two treatment groups at the end of the fourmonth study period [96]. This study was limited by its small sample size without involving all various ethnicities, a single dose of honey, lack of data on the effect of honey on postmenopausal symptoms, and short duration of the study.

Oxidative stress induced by oestrogen deficiency is postulated as one of the mechanisms leading to postmenopausal osteoporosis. Shafin et al. compared the effects of oestrogen-progestin therapy and Tualang honey in postmenopausal women [97]. In their study, Tualang honey supplementation for 16 weeks in postmenopausal women resulted in reduced oxidative stress as indicated by an increase in GPX or CAT activities and a decrease in 4hydroxynonenal (4-HNE) level, respectively, at an extent comparable to those who received oestrogen-progestin therapy [97]. This oestrogenic property of honey could protect against postmenopausal osteoporosis.

5.2. Effects of Combined Honey Supplementation and Exercise. A study was conducted by Ooi et al. to investigate the effects of combined aerobic dance exercise and honey supplementation on bone turnover markers [99]. A honey drink, prepared from $20 \mathrm{~g}$ Gelam honey diluted in $300 \mathrm{~mL}$ plain water, was consumed by the subjects in the honey group and honey plus aerobic dance exercise group, for seven days/week for a total of six weeks. The subjects in the honey plus aerobic dance exercise group and aerobic dance alone group were required to undergo aerobic dance sessions for three sessions per week, one hour per session. The results suggested that combined intervention caused a greater increase in alkaline phosphatase compared to aerobic dance exercise or honey supplementation alone [99]. In another study, the researchers investigated the effects of aerobic dance exercise plus Gelam honey supplementation on metabolism markers and muscular performance in adult women. It was found that the combination of aerobic dance exercise and honey supplementation suppressed the serum C-terminal telopeptide of type 1 collagen resulting from exercise, possibly enhancing the lower limb muscular power in sedentary women [99]. This finding was consistent with the previous animal study, which showed that the combined regime significantly reduced bone resorption [92].

\section{Conclusion}

The literature shows that honey has promising skeletalbeneficial effects in preventing osteoporosis. Many types of honey have been shown to prevent bone loss in various animal models via its high antioxidant and anti-inflammatory properties (Figure 1). Nevertheless, the efficacy 


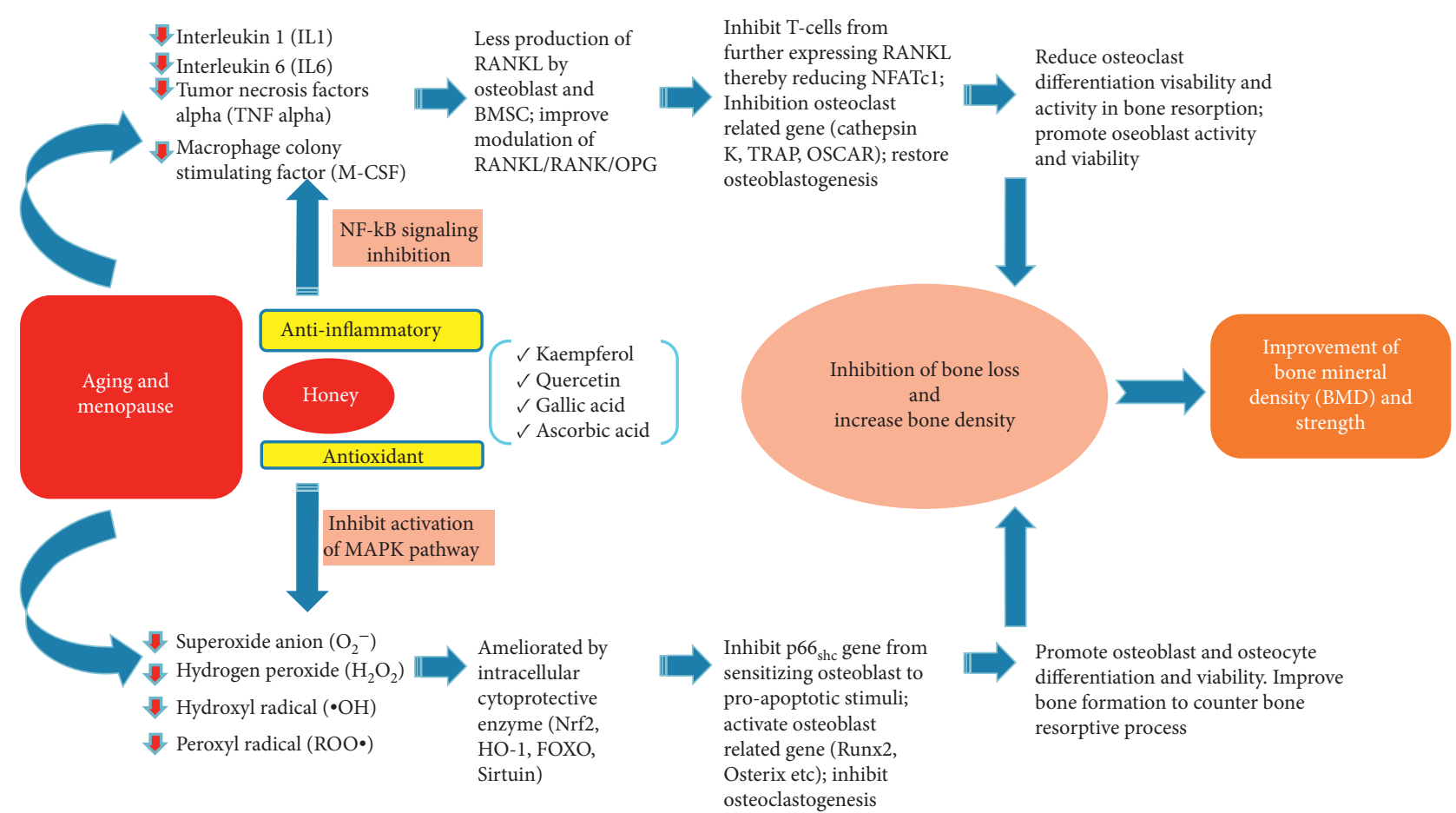

FIGURE 1: Potential effects of honey on bone health. Menopause and ageing give rise to oxidative stress and chronic low-grade inflammation, which cause bone loss. Phytochemical components found in honey, such as quercetin, kaempferol, gallic acid, and ascorbic acid, exert antioxidant and anti-inflammatory action by inhibiting activation of MAPK pathway and NF- $\kappa$ B signalling, respectively. This action will prevent the formation of osteoclasts and favour bone formation by osteoblasts, subsequently preserving bone density.

of honey seems to be dose-dependent, whereby very high or low dosage will not produce desirable results on the skeleton. We cannot conclude a single effective dose due to the heterogenicity of the study design and honey types. It should be acknowledged that the composition of honey varies according to types and commercial brands and not all will have similar effects to the bone. Types, purity, and chemical constituents need to be considered before applying honey for any health purposes. Nevertheless, this review can serve as guidance for choosing the appropriate honey and its doses in osteoporosis prevention. The limited number of human studies suggested that effort needs to be made to validate the effects of honey in human, especially postmenopausal women. Particularly, long-term data are needed to show that honey consumption can lead to decreased bone loss and fracture risk.

\section{Conflicts of Interest}

The authors declare that there are no conflicts of interest regarding the publication of this paper.

\section{Acknowledgments}

We thank Universiti Kebangsaan Malaysia for funding the researchers through grant GUP-2017-060.

\section{References}

[1] N. C. Wright, A. C. Looker, K. G. Saag et al., "The recent prevalence of osteoporosis and low bone mass in the United States based on bone mineral density at the femoral neck or lumbar spine," Journal of Bone and Mineral Research, vol. 29, no. 11, pp. 2520-2526, 2014.

[2] D. K. Dhanwal, C. Cooper, and E. M. Dennison, "Geographic variation in osteoporotic hip fracture incidence: the growing importance of Asian influences in coming decades," Journal of Osteoporosis, vol. 2010, Article ID 757102, 5 pages, 2010.

[3] A. Mithal, B. Bansal, C. Kyer, and P. Ebeling, "The Asia-pacific regional audit-epidemiology, costs, and burden of osteoporosis in India 2013: a report of international osteoporosis foundation," Indian Journal of Endocrinology and Metabolism, vol. 18, no. 4, p. 449, 2014.

[4] A. Mithal and P. Ebeling, The Asia-Pacific Regional Audit: Epidemiology, Costs \& Burden of Osteoporosis in 2013, International Osteoporosis Foundation, Nyon, Switzerland, 2013.

[5] A. Mithal and E. Lau, The Asian Audit Epidemiology, Costs and Burden of Osteoporosis in Asia 2009. The Asia-Pacific Regional Audit: Epidemiology, Costs \& Burden of Osteoporosis in 2009, International Osteoporosis Foundation, Nyon, Switzerland, 2009.

[6] I. Mirończuk-Chodakowska, A. M. Witkowska, and M. E. Zujko, "Endogenous non-enzymatic antioxidants in the human body," Advances in Medical Sciences, vol. 63, no. 1, pp. 68-78, 2018.

[7] L. G. Rao and A. V. Rao, "Oxidative stress and antioxidants in the risk of osteoporosis-role of the antioxidants lycopene and polyphenols," Topics in Osteoporosis, vol. 5, pp. 117-144, 2013.

[8] D. A. Callaway and J. X. Jiang, "Reactive oxygen species and oxidative stress in osteoclastogenesis, skeletal aging and bone diseases," Journal of Bone and Mineral Metabolism, vol. 33, no. 4, pp. 359-370, 2015. 
[9] D.-Z. Li, Q.-X. Zhang, X.-X. Dong, H.-D. Li, and X. Ma, "Treatment with hydrogen molecules prevents RANKL-induced osteoclast differentiation associated with inhibition of ROS formation and inactivation of MAPK, AKT and NFkappa B pathways in murine RAW264.7 cells," Journal of Bone and Mineral Metabolism, vol. 32, no. 5, pp. 494-504, 2013.

[10] H. Kanzaki, F. Shinohara, I. Kanako et al., "Molecular regulatory mechanisms of osteoclastogenesis through cytoprotective enzymes," Redox Biology, vol. 8, pp. 186-191, 2016.

[11] Y. Jin, X. Liu, H. Liu et al., "Oxidative stress-induced apoptosis of osteoblastic MC3T3-E1 cells by hydroxyapatite nanoparticles through lysosomal and mitochondrial pathways," RSC Advances, vol. 7, no. 21, pp. 13010-13018, 2017.

[12] S. Deng, G. Dai, S. Chen et al., "Dexamethasone induces osteoblast apoptosis through ROS-PI3K/AKT/GSK3 $\beta$ signaling pathway," Biomedicine \& Pharmacotherapy, vol. 110, pp. 602-608, 2019.

[13] B. Zhang, Q. Y. Xie, Y. Quan, X. M. Pan, and D. F. Liao, "Reactive oxygen species induce cell death via Akt signaling in rat osteoblast-like cell line ROS 17/2.8," Toxicology and Industrial Health, vol. 31, no. 12, pp. 1236-1242, 2015.

[14] D. Flegar, A. Šućur, A. Markotić, N. Kovačić, and D. Grčević, "Osteoporosis in the view of osteoimmunology: common feature underlined by different pathogenic mechanisms," Periodicum biologorum, vol. 117, no. 1, pp. 35-43, 2015.

[15] P. Pietschmann, D. Mechtcheriakova, A. Meshcheryakova, U. Föger-Samwald, and I. Ellinger, "Immunology of osteoporosis: a mini-review," Gerontology, vol. 62, no. 2, pp. 128137, 2016.

[16] P. P. C. Souza and U. H. Lerner, "The role of cytokines in inflammatory bone loss," Immunological Investigations, vol. 42, no. 7, pp. 555-622, 2013.

[17] M. Tencerova and M. Kassem, "The bone marrow-derived stromal cells: commitment and regulation of adipogenesis," Frontiers in Endocrinology, vol. 7, 2016.

[18] National Coordinating Committee on Food and Nutrition, Recommeded Nutrient Intake for Malaysia, Ministry of Health, Putrajaya, Malaysia, 2017.

[19] M. J. Bolland, A. Grey, A. Avenell, G. D. Gamble, and I. R. Reid, "Calcium supplements with or without vitamin D and risk of cardiovascular events: reanalysis of the Women's Health Initiative limited access dataset and meta-analysis," BMJ, vol. 342, Article ID d2040, 2011.

[20] R. A. Gibson, M. Makrides, L. G. Smithers, M. Voevodin, and A. J. Sinclair, "The effect of dairy foods on CHD: a systematic review of prospective cohort studies," British Journal of Nutrition, vol. 102, no. 9, pp. 1267-1275, 2009.

[21] J. Alvarez-Suarez, M. Gasparrini, T. Forbes-Hernández, L. Mazzoni, and F. Giampieri, "The composition and biological activity of honey: a focus on manuka honey," Foods, vol. 3, no. 3, pp. 420-432, 2014.

[22] J. M. Alvarez-Suarez, Bee Products-Chemical and Biological Properties, Springer International Publishing, Basel, Switzerland, 2017.

[23] J. M. Alvarez-Suarez, S. Tulipani, S. Romandini, E. Bertoli, and M. Battino, "Contribution of honey in nutrition and human health: a review," Mediterranean Journal of Nutrition and Metabolism, vol. 3, no. 1, pp. 15-23, 2010.

[24] P. M. Da Silva, C. Gauche, L. V. Gonzaga, A. C. O. Costa, and R. Fett, "Honey: chemical composition, stability and authenticity," Food Chemistry, vol. 196, pp. 309-323, 2016.
[25] M. G. Miguel, M. D. Antunes, and M. L. Faleiro, "Honey as a complementary medicine," Integrative Medicine Insights, vol. 12, Article ID 117863371770286, 2017.

[26] D. Cianciosi, T. Forbes-Hernández, S. Afrin et al., "Phenolic compounds in honey and their associated health benefits: a review," Molecules, vol. 23, no. 9, p. 2322, 2018.

[27] T. Eteraf-Oskouei and M. Najafi, "Traditional and modern uses of natural honey in human diseases: a review," Iranian Journal of Basic Medical Sciences, vol. 16, no. 6, pp. 731-742, 2013.

[28] S. P. Kek, N. L. Chin, Y. A. Yusof, S. W. Tan, and L. S. Chua, "Total phenolic contents and colour intensity of Malaysian honeys from the Apis spp. and trigona spp. bees," Agriculture and Agricultural Science Procedia, vol. 2, pp. 150-155, 2014.

[29] L. D. O. Sant'Ana, A. B. B. Ferreira, M. C. A. Lorenzon, R. L. L. Berbara, and R. N. Castro, "Correlation of total phenolic and flavonoid contents of brazilian honeys with colour and antioxidant capacity," International Journal of Food Properties, vol. 17, no. 1, pp. 65-76, 2014.

[30] M. Dzugan, M. Tomczyk, P. Sowa, and D. Grabek-Lejko, "Antioxidant activity as biomarker of honey variety," Molecules, vol. 23, no. 8, p. 2069, 2018.

[31] S. Ahmed, S. A. Sulaiman, A. A. Baig et al., "Honey as a potential natural antioxidant medicine: an insight into its molecular mechanisms of action," Oxidative Medicine and Cellular Longevity, vol. 2018, Article ID 8367846, 19 pages, 2018.

[32] O. O. Erejuwa, S. A. Sulaiman, and M. S. Ab Wahab, "Honey: a novel antioxidant," Molecules, vol. 17, no. 4, pp. 4400-4423, 2012.

[33] A. Oryan, E. Alemzadeh, and A. Moshiri, "Biological properties and therapeutic activities of honey in wound healing: a narrative review and meta-analysis," Journal of Tissue Viability, vol. 25, no. 2, pp. 98-118, 2016.

[34] M. Musa Özcan and F. Al Juhaimi, "Honey as source of natural antioxidants," Journal of Apicultural Research, vol. 54, no. 3, pp. 145-154, 2015.

[35] C. B. Abd Aziz, S. Q. Ahmad Suhaimi, H. Hasim, A. H. Ahmad, I. Long, and R. Zakaria, "Effects of Tualang honey in modulating nociceptive responses at the spinal cord in offspring of prenatally stressed rats," Journal of Integrative Medicine, vol. 17, no. 1, pp. 66-70, 2019.

[36] E. Torre, "Molecular signaling mechanisms behind polyphenol-induced bone anabolism," Phytochemistry Reviews, vol. 16, no. 6, pp. 1183-1226, 2017.

[37] A. Rahal, A. Kumar, V. Singh et al., "Oxidative stress, prooxidants, and antioxidants: the interplay," BioMed Research International, vol. 2014, Article ID 761264, 19 pages, 2014.

[38] M. D. Hadagali and L. S. Chua, "The anti-inflammatory and wound healing properties of honey," European Food Research and Technology, vol. 239, no. 6, pp. 1003-1014, 2014.

[39] M. Mueller, S. Hobiger, and A. Jungbauer, "Anti-inflammatory activity of extracts from fruits, herbs and spices," Food Chemistry, vol. 122, no. 4, pp. 987-996, 2010.

[40] M. Kassim, M. Achoui, M. Mansor, and K. M. Yusoff, "The inhibitory effects of Gelam honey and its extracts on nitric oxide and prostaglandin $\mathrm{E}_{2}$ in inflammatory tissues," Fitoterapia, vol. 81, no. 8, pp. 1196-1201, 2010.

[41] S. Z. Hussein, K. M. Yusoff, S. Makpol, Y. Anum, and M. Yusof, "Gelam honey inhibits the production of proinflammatory, mediators NO, PGE 2, TNF- $\alpha$, and IL-6 in carrageenan-induced acute paw edema in rats," Evidence- 
Based Complementary and Alternative Medicine, vol. 2012, Article ID 109636, 13 pages, 2012.

[42] B. V. Owoyele and A. Soladoye, "Effects of honey on inflammation and nitric oxide production in Wistar rats," Journal of Chinese Integrative Medicine, vol. 9, no. 4, pp. 447-452, 2011.

[43] M. Kassim, M. Achoui, M. R. Mustafa, M. A. Mohd, and K. M. Yusoff, "Ellagic acid, phenolic acids, and flavonoids in Malaysian honey extracts demonstrate in vitro anti-inflammatory activity," Nutrition Research, vol. 30, no. 9, pp. 650-659, 2010.

[44] H. Z. Nooh and N. M. Nour-eldien, "The dual anti-inflammatory and antioxidant activities of natural honey promote cell proliferation and neural regeneration in a rat model of colitis," Acta Histochemica, vol. 118, no. 6, pp. 588-595, 2016.

[45] J. C. Ruiz-ruiz, A. J. Matus-basto, P. Acereto-Escoffié, and M. R. Segura-Campos, "Antioxidant and anti-inflammatory activities of phenolic compounds isolated from Melipona beecheii honey," Food and Agricultural Immunology, vol. 28, no. 6, pp. 1424-1437, 2017.

[46] S. Z. Hussein, K. M. Yusoff, S. Makpol, Y. Anum, and M. Yusof, "Gelam honey attenuates carrageenan-induced rat paw inflammation via NF- $\kappa$ B pathway," PLoS One, vol. 8, no. 8, Article ID e72365, 2013.

[47] L. A. BenSaad, K. H. Kim, C. C. Quah, W. R. Kim, and M. Shahimi, "Anti-inflammatory potential of ellagic acid, gallic acid and punicalagin $A \& B$ isolated from Punica granatum," BMC Complementary and Alternative Medicine, vol. 17, no. 1, pp. 1-10, 2017.

[48] M. Tanaka, Y. Kishimoto, M Sasaki et al., "Terminalia bellirica (Gaertn.) roxb. Extract and gallic acid attenuate LPS-induced inflammation and oxidative stress via MAPK/NF- $\kappa \mathrm{B}$ and akt/ AMPK/Nrf2 pathways," Oxidative Medicine and Cellular Longevity, vol. 2018, Article ID 9364364, 15 pages, 2018.

[49] A. Bustami, P. Sopiah, R. Muharam, and H. Wibowo, "Effects of gallic acid and its derivates on inflammatory regulation of endometriotic primary cultures: study on NF- $\kappa \mathrm{B}$ mRNA expression and IL-6 secretion," Biomedical and Pharmacology Journal, vol. 11, no. 3, pp. 1479-1484, 2018.

[50] W.-K. Jung, D.-Y. Lee, J.-H. Kim et al., “Anti-inflammatory activity of caffeic acid phenethyl ester (CAPE) extracted from Rhodiola sacra against lipopolysaccharide-induced inflammatory responses in mice," Process Biochemistry, vol. 43, no. 7, pp. 783-787, 2008.

[51] H. G. Choi, P. T. Tran, J.-H. Lee, B. S. Min, and J. A. Kim, "Anti-inflammatory activity of caffeic acid derivatives isolated from the roots of Salvia miltiorrhiza Bunge," Archives of Pharmacal Research, vol. 41, no. 1, pp. 64-70, 2018.

[52] Z. N. Yin, W. J. Wu, C. Z Sun et al., "Antioxidant and antiinflammatory capacity of ferulic acid released from wheat bran by solid-state fermentation of Aspergillus Niger," Biomedical and Environmental Sciences, vol. 32, no. 1, pp. 11-21, 2019.

[53] S. Zhang, P. Wang, P. Zhao et al., "Pretreatment of ferulic acid attenuates inflammation and oxidative stress in a rat model of lipopolysaccharide-induced acute respiratory distress syndrome," International Journal of Immunopathology and Pharmacology, vol. 31, Article ID 394632017750518, 2018.

[54] X. Zheng, Y. Cheng, Y. Chen et al., "Ferulic acid improves depressive-like behavior in prenatally-stressed offspring rats via anti-inflammatory activity and HPA axis," International Journal of Molecular Sciences, vol. 20, no. 3, p. 493, 2019.
[55] Y. Li, L. Zhang, X. Wang, W. Wu, and R. Qin, "Effect of Syringic acid on antioxidant biomarkers and associated inflammatory markers in mice model of asthma," Drug Development Research, vol. 80, no. 2, pp. 253-261, 2019.

[56] M. S. Ellulu, A. Rahmat, P. Ismail, H. Khaza'ai, and Y. Abed, "Effect of vitamin $\mathrm{C}$ on inflammation and metabolic markers in hypertensive and/or diabetic obese adults: a randomized controlled trial," Drug Design, Development and Therapy, vol. 9, pp. 3405-3412, 2015.

[57] X. Cao, Y. Jin, H. Zhang et al., "The anti-inflammatory effects of 4-((5-Bromo-3-chloro-2-hydroxybenzyl) amino)-2-hydroxybenzoic acid in lipopolysaccharide-activated primary microglial cells," Inflammation, vol. 41, no. 2, pp. 530-540, 2018.

[58] J.-K. Lee, S. Lee, T.-Y. Shin, D. Khang, and S.-H. Kim, "Antiinflammatory effect of $o$-vanillic acid on lipopolysaccharidestimulated macrophages and inflammation models," Journal of Food and Nutrition Research, vol. 6, no. 4, pp. 227-233, 2018.

[59] S. S. Singh, S. N. Rai, H. Birla et al., "Effect of chlorogenic acid supplementation in MPTP-intoxicated mouse," Frontiers in Pharmacologyl, vol. 9, pp. 1-15, 2018.

[60] E. C. O. Da Silva, F. M. dos Santos, A. R. B. Ribeiro, S. T. de Souza, E. Barreto, and E. J. D. S. Fonseca, "Druginduced anti-inflammatory response in A549 cells, as detected by Raman spectroscopy: a comparative analysis of the actions of dexamethasone and p-coumaric acid," The Analyst, vol. 144, no. 5, pp. 1622-1631, 2019.

[61] M. G. Rahbardar, B. Amin, S. Mehri, S. J. Mirnajafi-Zadeh, and H. Hosseinzadeh, "Anti-inflammatory effects of ethanolic extract of Rosmarinus officinalis $\mathrm{L}$. and rosmarinic acid in a rat model of neuropathic pain," Biomedicine \& Pharmacotherapy, vol. 86, pp. 441-449, 2017.

[62] R. Zhang, J. Xu, J. Zhao, and Y. Chen, "Genistein improves inflammatory response and colonic function through NF- $\kappa \mathrm{B}$ signal in DSS-induced colonic injury," Oncotarget, vol. 8, no. 37, pp. 61385-61392, 2017.

[63] D. Chen, A. Bi, X. Dong et al., "Luteolin exhibits anti-inflammatory effects by blocking the activity of heat shock protein 90 in macrophages," Biochemical and Biophysical Research Communications, vol. 443, no. 1, pp. 326-332, 2014.

[64] E. S. M. Ang, X. Yang, H. Chen, Q. Liu, M. H. Zheng, and $\mathrm{J}$. $\mathrm{Xu}$, "Naringin abrogates osteoclastogenesis and bone resorption via the inhibition of RANKL-induced NF- $\kappa$ B and ERK activation," FEBS Letters, vol. 585, no. 17, pp. 2755-2762, 2011.

[65] X. Y. Ai, Y. Qin, H. J. Liu et al., “Apigenin inhibits colonic inflammation and tumorigenesis by suppressing STAT3-NF$\kappa \mathrm{B}$ signaling," Oncotarget, vol. 8, no. 59, pp. 100216-100226, 2017.

[66] C. Wu, W. Wang, B. Tian et al., "Myricetin prevents titanium particle-induced osteolysis in vivo and inhibits RANKL-induced osteoclastogenesis in vitro," Biochemical Pharmacology, vol. 93, no. 1, pp. 59-71, 2015.

[67] M. J. Yeon, M. H. Lee, D. H. Kim et al., “Anti-inflammatory effects of Kaempferol on Helicobacter pylori-induced inflammation," Bioscience, Biotechnology, and Biochemistry, vol. 83, no. 1, pp. 166-173, 2019.

[68] Y. J. Kim and W. Park, "Anti-inflammatory effect of quercetin on RAW 264.7 mouse macrophages induced with polyinosinicpolycytidylic acid," Molecules, vol. 21, no. 4, p. 450, 2016.

[69] R. Afroz, E. M. Tanvir, S. Paul, N. C. Bhoumik, S. H. Gan, M. D. I. Khalil et al., "DNA damage inhibition properties of sundarban honey and its phenolic composition," Journal of Food Biochemistry, vol. 40, no. 4, pp. 436-445, 2016. 
[70] R. Afroz, E. M. Tanvir, W. Zheng, and P. Little, "Molecular pharmacology of honey," Clinical and Experimental Pharmacology, vol. 6, no. 3, p. 212, $2016 \mathrm{~b}$.

[71] R. Mitamura, H. Hara, and Y. Aoyama, "Ingestion of raffinose promotes calcium absorption in the large intestine of rats," Bioscience, Biotechnology, and Biochemistry, vol. 68, no. 2, pp. 384-389, 2004.

[72] S. Bogdanov, C. Lüllmann, P. Martin et al., "Honey quality and international regulatory standards: review by the international honey commission," Bee World, vol. 80, no. 2, pp. 61-69, 1999.

[73] M. W. Ariefdjohan, B. R. Martin, P. J. Lachcik, and C. M. Weaver, "Acute and chronic effects of honey and its carbohydrate constituents on calcium absorption in rats," Journal of Agricultural and Food Chemistry, vol. 56, no. 8, pp. 2649-2654, 2008.

[74] M. O. Abioja, K. B. Ogundimu, T. E. Akibo et al., "Growth, mineral deposition, and physiological responses of broiler chickens offered honey in drinking water during hot-dry season," International Journal of Zoology, vol. 2012, Article ID 403502, 6 pages, 2012.

[75] L. Chepulis and N. Starkey, "The long-term effects of feeding honey compared with sucrose and a sugar-free diet on weight gain, lipid profiles, and DEXA measurements in rats," Journal of Food Science, vol. 73, no. 1, pp. H1-H7, 2008.

[76] J. M. Lean, J. T. Davies, K. Fuller et al., "A crucial role for thiol antioxidants in estrogen-deficiency bone loss," Journal of Clinical Investigation, vol. 112, no. 6, pp. 915-923, 2003.

[77] T. Komori, "Animal models for osteoporosis," European Journal of Pharmacology, vol. 759, pp. 287-294, 2015.

[78] M. Prideaux, D. M. Findlay, and G. J. Atkins, "Osteocytes: the master cells in bone remodelling," Current Opinion in Pharmacology, vol. 28, pp. 24-30, 2016.

[79] S. S. M. Zaid, S. A. Sulaiman, K. N. M. Sirajudeen, and N. H. Othman, "The effects of tualang honey on female reproductive organs, tibia bone and hormonal profile in ovariectomised rats-animal model for menopause," BMC Complementary and Alternative Medicine, vol. 10, no. 1, p. 82, 2010.

[80] S. S. M. Zaid, S. A. Sulaiman, N. H. Othman et al., "Protective effects of Tualang honey on bone structure in experimental postmenopausal rats," Clinics, vol. 67, no. 7, pp. 779-784, 2012.

[81] S. Swift, L. M. Chepulis, B. Uy, and F. J. Radcliff, "Enhanced antibacterial activity of MGOTM manuka honey complexed with a-cyclodextrin (manuka honey with CycloPowerTM)," Functional Foods in Health and Disease, vol. 4, no. 5, pp. 172-181, 2014.

[82] M. Katia and C. Giancarlo, Cyclodextrins. Handbook of Analysis of Active Compounds in Functional Foods, CRC Press, Boca Raton, FL, USA, 2012.

[83] S. Katsumata, F. M. Wolber, M. Tadaishi, Y. Tousen, Y. Ishimi, and M. C. Kruger, "Effects of manuka honey combined with $\alpha$-cyclodextrin on bone metabolism and caecal bacterial contents in ovariectomized mice," International Journal of Food and Nutritional Science, vol. 2, no. 2, pp. 86-91, 2015.

[84] I. S. Yudaniayanti, H. Primarizky, and L. Nangoi, "The effects of honey (Apis dorsata) supplements on increased bone strength in ovariectomized rat as animal model of osteoporosis," AIP Conference Proceedings, vol. 1945, no. 1, 2018.

[85] M. H. R. Ibrahim, A. H. Hasib, S. N. Rohmah, S. Abani, S. Yordan, and I. S. Yudaniayanti, "Utilization of honey Apis dorsata as antiosteoporosis on requirements of bone calcium ash density on ovariohysterectomized white rat (ratus norvegicus)," KnE Life Sciences, vol. 3, no. 6, p. 627, 2017.
[86] A. Bigham-sadegh, I. Karimi, F. Hoseini, A. Oryan, and S. Sharifi, "Effects of honey and hydroxyapatite on bone healing in rats," Trauma Monthly, vol. 23, no. 4, Article ID e56119, 2018.

[87] F. Hajizadeh, B. Derakhshan, A. Peimani, and Z. Abbasi, "Effect of topical honey on mandibular bone defect healing in rats," The Journal of Contemporary Dental Practice, vol. 19, no. 1, pp. 47-51, 2018.

[88] A. Gunduz, S. Turedi, R. M. Russell, and F. A. Ayaz, "Clinical review of grayanotoxin/mad honey poisoning past and present," Clinical Toxicology, vol. 46, no. 5, pp. 437-442, 2008.

[89] A. Sahin, S. Turkmen, N. Guzel et al., "A comparison of the effects of grayanotoxin-containing honey (mad honey), normal honey, and propolis on fracture healing," Medical Principles and Practice, vol. 27, no. 2, pp. 99-106, 2018.

[90] F. K. Ooi, L. Hung, and Y. He, “Tibial bone mineral density, geometry and mechanical properties in response to high impact exercise and honey supplementation in rats," Asian Journal of Exercise and Sports Science, vol. 11, no. 2, pp. 11-24, 2014.

[91] S. S. Tavafzadeh, F.-K. Ooi, O. Krasilshchikov, and S. A. Sulaima, "Effect of a combination of jumping exercise and honey supplementation on the mass, strength and physical dimensions of bones in young female rats," Journal of ApiProduct and ApiMedical Science, vol. 3, pp. 26-32, 2010.

[92] S. S. Tavafzadeh, F. K. Ooi, C. K. Chen, S. A. Sulaiman, and L. K. Hung, "Changes in bone metabolism and antioxidant status with combined exercise and honey supplementation in young female rats," Journal of Exercise, Sports \& Orthopedics, vol. 2, no. 2, pp. 1-8, 2015.

[93] S. S. Tavafzadeh, F. K. Ooi, C. K. Chen, S. A. Sulaiman, and L. K. Hung, "Bone mechanical properties and mineral density in response to cessation of jumping exercise and honey supplementation in young female rats," BioMed Research International, vol. 2015, Article ID 938782, 8 pages, 2015.

[94] M. Mosavat, F. K. Ooi, and M. Mohamed, "Effects of honey supplementation combined with different jumping exercise intensities on bone mass, serum bone metabolism markers and gonadotropins in female rats," BMC Complementary and Alternative Medicine, vol. 14, no. 1, p. 126, 2014.

[95] M. Mosavat, F. K. Ooi, and M. Mohamed, "Stress hormone and reproductive system in response to honey supplementation combined with different jumping exercise intensities in female rats," BioMed Research International, vol. 2014, Article ID 123640, 6 pages, 2014.

[96] N. H. Nik Hussain, S. A. Sulaiman, I. Idiana Hassan et al., "Randomized controlled trial on the effects of tualang honey and hormonal replacement therapy (HRT) on cardiovascular risk factors, hormonal profiles and bone density among postmenopausal women: a pilot study," Journal of Food Research, vol. 1, no. 2, pp. 171-188, 2012.

[97] N. Shafin, Z. Othman, R. Zakaria, and N. H. Nik Hussain, "Tualang honey supplementation reduces blood oxidative stress levels/activities in postmenopausal women," ISRN Oxidative Medicine, vol. 2014, Article ID 364836, 4 pages, 2014.

[98] F. K. Ooi, N. bt Ismail, and M. Y. bt Abdullah, "Effects of combined aerobic dance exercise and honey supplementation on bone turnover markers in young females," Asian Journal of Exercise and Sports Science, vol. 8, no. 1, pp. 53-63, 2011.

[99] M. Rahim, F. K. Ooi, and W. Z. W. A. Hamid, "Changes of bone metabolism markers and muscular performance with combined aerobic dance exercise and honey supplementation in adult women," Sports and Exercise Medicine-Open Journal, vol. 1, no. 6, pp. 186-197, 2016. 


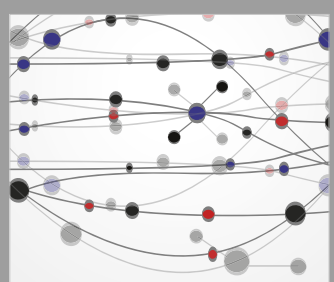

The Scientific World Journal
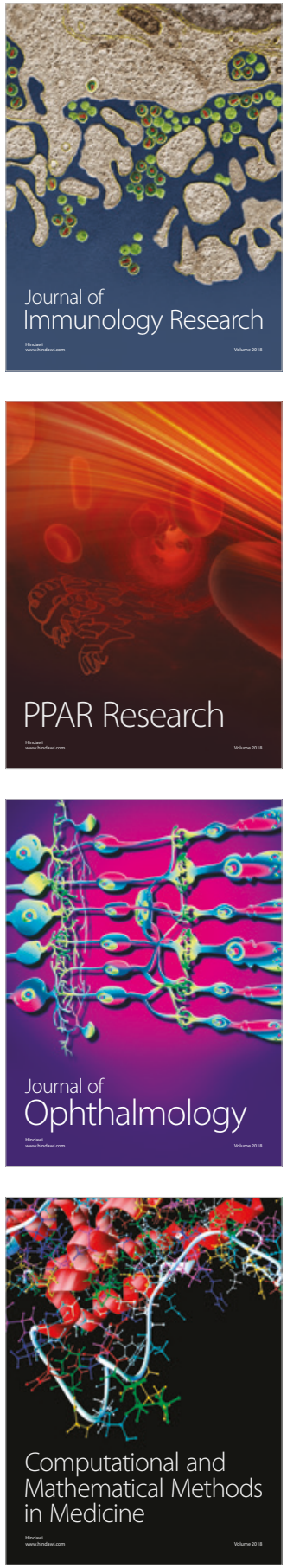

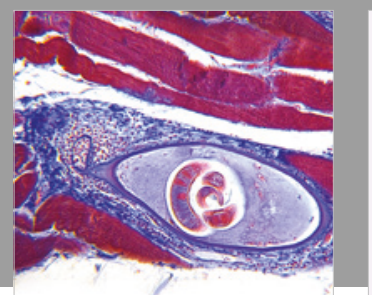

Gastroenterology Research and Practice

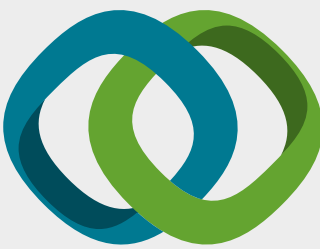

\section{Hindawi}

Submit your manuscripts at

www.hindawi.com
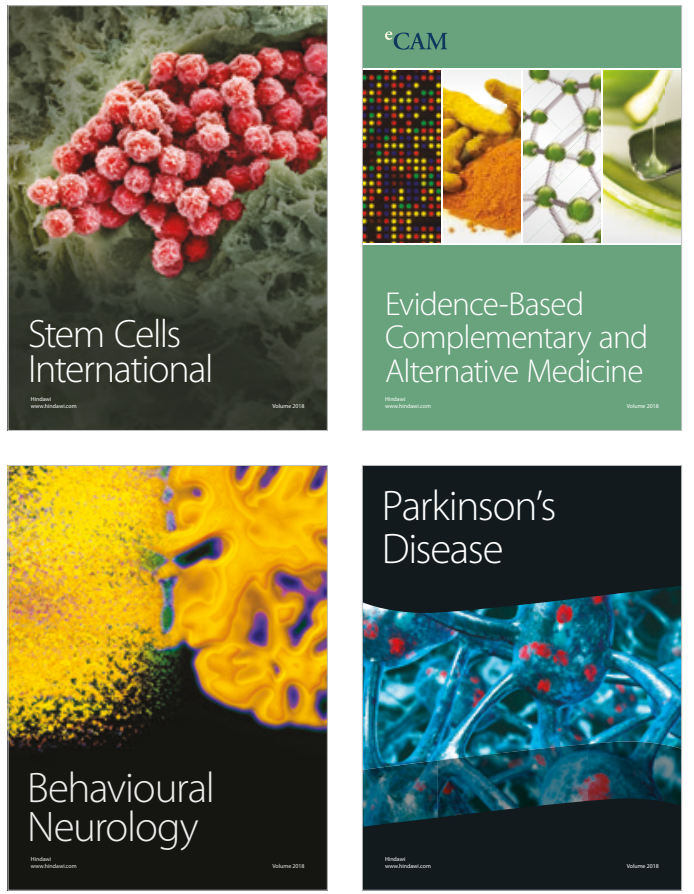

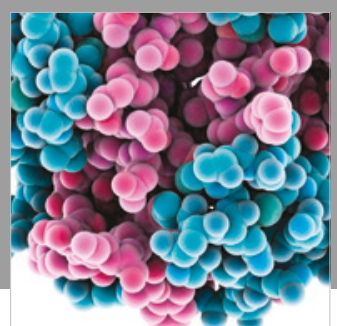

ournal of

Diabetes Research

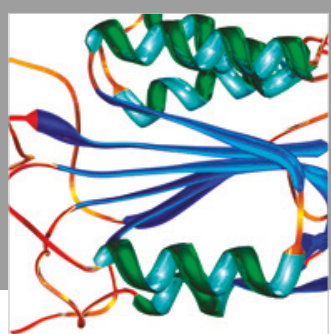

Disease Markers
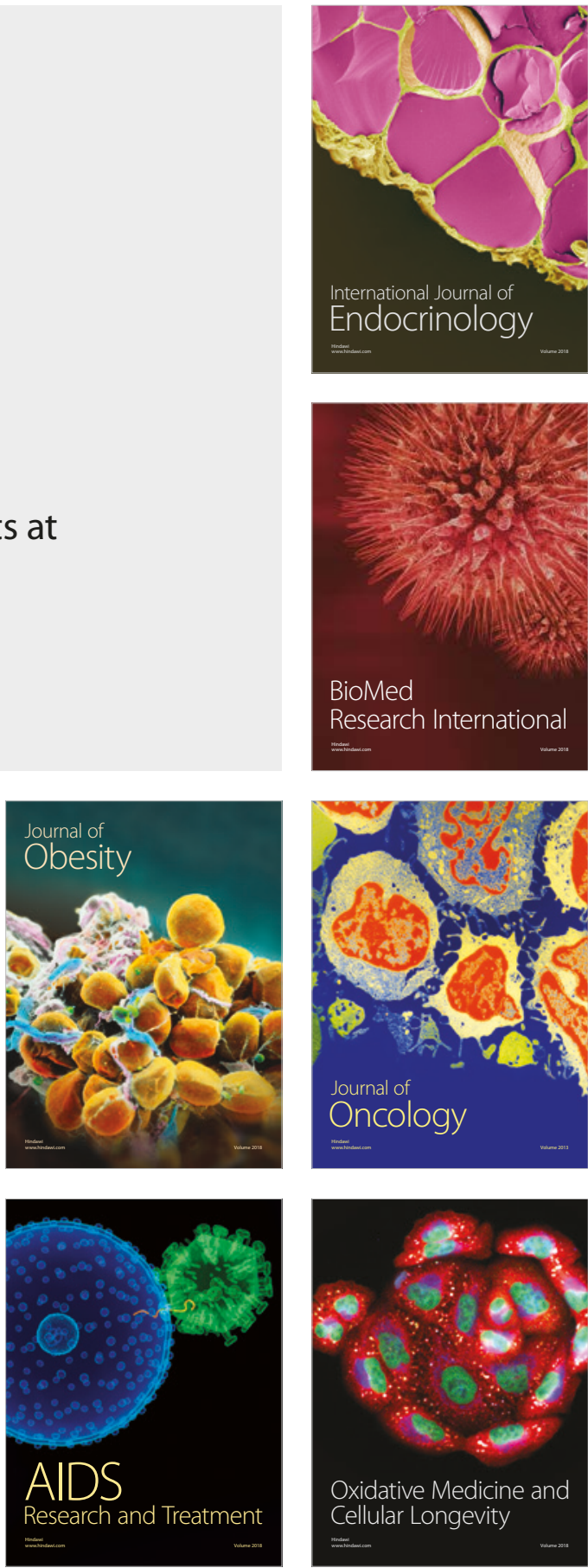